\title{
Biomarkers of Internal Origin and Their Significance in Diabetes and Diabetic Complications
}

\author{
Sai YRKM ${ }^{1 *}$, Dattatreya $A^{1}$, Anand $S Y^{1}$, SureshBabu $D^{2}$ and Sandeep Heni RS ${ }^{3}$ \\ ${ }^{1}$ Gitam Institute of Sciences, GITAM University, Gandhinagar, Rushikonda, Visakhapatnam, India \\ ${ }^{2}$ School of Life sciences, Centre for Bioinformatics, Pondicherry University, Pondicherry, India \\ ${ }^{3}$ Adithya PG College, Andhra University (Affil.), KAKINADA, East Godavari Dist, India
}

\begin{abstract}
This review is an overview on the modern diagnostic and prognostic biomarkers' for Diabetes and Diabetic complications. Here in this article we took various modernized and modern biomarkers' at a glance and had some hypothesis on the implications and also their pertinence of use in other appliances for the peculiar results of Interpretations. The prominent functions of certain biomarkers may give a conclusion that the dysfunction ability of it may give rise to severe and serious molestations. This indeed concludes in very sarcastic way that the marker itself is a reliever of the problem. Some does not intend themselves to be markers' but they'll be markers' in the diagnostic methods. This review prevails and perturbs the omnifarious biomarkers' in Diabetic complications.
\end{abstract}

\section{Introduction}

\section{Diabetes mellitus}

Diabetes mellitus is a disease of abnormal glucose metabolism resulting in hyperglycemia due to either a deficiency of insulin secretion or insulin resistance or both. Classic signs and symptoms of diabetes include polyuria, polydipsia, polyphagia, weight loss, headache, tachycardia, palpitations, and blurred vision. The diagnostic criteria for determining diabetes have recently been changed in order to increase the sensitivity of the test. Currently, diabetes is diagnosed by a fasting glucose of $126 \mathrm{mg} / \mathrm{dl}$ or a random glucose of $200 \mathrm{mg} / \mathrm{dl}$ Impaired fasting glucose (IFG) is defined as a blood sugar of $100-125 \mathrm{mg} / \mathrm{dl}$ (5.6-6.9 $\mathrm{mmol} / \mathrm{l}$ ), Impaired glucose tolerance (IGT) is defined as an abnormal 2-hour postprandial blood sugar of $144-199 \mathrm{mg} / \mathrm{dl}$ which is due to insulin resistance as one of the cause for diabetes [1] which in turn results due to disturbances of lipid metabolism, in contrasts with them a new device (EZSCAN) developed to evaluate sudomotor function which is useful in the prediction of the future abnormalities in Glucose tolerance which is the measure of pre-diabetes [2]. It is important to note that children with diabetes usually present with acute signs and symptoms, including coma or loss of consciousness, critical glucose levels, ketonemia, and marked glucosuria and ketonuria. The diagnosis in children is made immediately (rather than repeating a blood sugar). Obesity indices are BMI to Waist, etc anthropometric indices should be monitored with certain guidelines [3], as, a legion study different from that of latter one is being done, which states that, in contrast to the latter, people are still lagging in diabetic control from guidelines, but no worse than in countries in the Middle East [4]. Overweight and obesity were both labels for series of weight, greater than what is generally considered healthy for an individual. BMI ranges for children and teens above a normal weight have different labels (at risk of overweight). Excess body weight is implicated as a risk factor for many disorders including heart disease, cancer, diabetes, female infertility, prostate enlargement, uterine fibroids, gallstone and gestational diabetes etc. Dozens of controlled clinical trials were carried out to determine the effect of weight loss on fasting blood glucose, where, only certain percent of adults lost at least $5 \%$ of their initial weight according to ADA recommendations. With maximum percent of adults gaining weight, it is recommended that more emphasis should be placed on weight loss as part of initial management of diabetes type II in public health settings [5]. Despite the enormity of the obesity pandemic, there are currently only two FDA-approved therapies; Prieurianin is a plant limonoid product, which causes weight loss by reducing energy intake in obese mice on high calorie diet [6]. In contrast with it Physical exercise has also been noticed as the tool for the decrease in glycemia levels [7].

The above criteria of these diagnostic methods were more frequently seen in developing countries. The others were developing few methods which include the molecular level diagnostic tests by the help of Biomarkers'. This is the time and may called as an 'ERA of Biomarkers'.

\section{Overview on Biomarkers}

The study of cancer biomarker proteins began in 1847 with the discovery by Henry Bence-Jones of what turned out, more than 100 years later, to be a tumor-produced free antibody light chain "Bence -Jones protein" in the urine of a multiple myeloma patient $[8,9]$ where it was present in large quantities and could be revealed by simple heat denaturation. One hundred and 40 years later this protein was demonstrated to be present also in the serum and in 1998 a routine immunodiagnostic test was approved by the FDA. Some of the bioindicators or most probably called as biomarkers' of Diabetes will be discussed in this review, where this chapter of Biomarkers' is on Internal Factors or Internal biomarkers' inside the human body with the brief explanation on Immunological, Molecular, serological, gene and signaling level, protein and pregnancy biomarkers in diabetic complications (Table 1).

\section{Immunological Biomarkers}

Periodontal inflammations are one of the complications given rise from that of the Diabetes. By evaluated study on level of associations

*Corresponding author: Sai YRKM, GITAM Institute of Sciences, GITAM University, Vishakapatnam, A.P, India, Tel: +91 9160066147, Email: saiyrkm2454@ gmail.com

Received July 29, 2011; Accepted August 20, 2011; Published August 25, 2011

Citation: Sai YRKM, Dattatreya A, Anand SY, SureshBabu D, Sandeep Hen RS (2011) Biomarkers of Internal Origin and Their Significance in Diabetes and Diabetic Complications. J Diabetes Metab R1:001. doi:10.4172/2155-6156.R1-001

Copyright: ( 2011 Sai YRKM, et al. This is an open-access article distributed under the terms of the Creative Commons Attribution License, which permits unrestricted use, distribution, and reproduction in any medium, provided the original author and source are credited. 


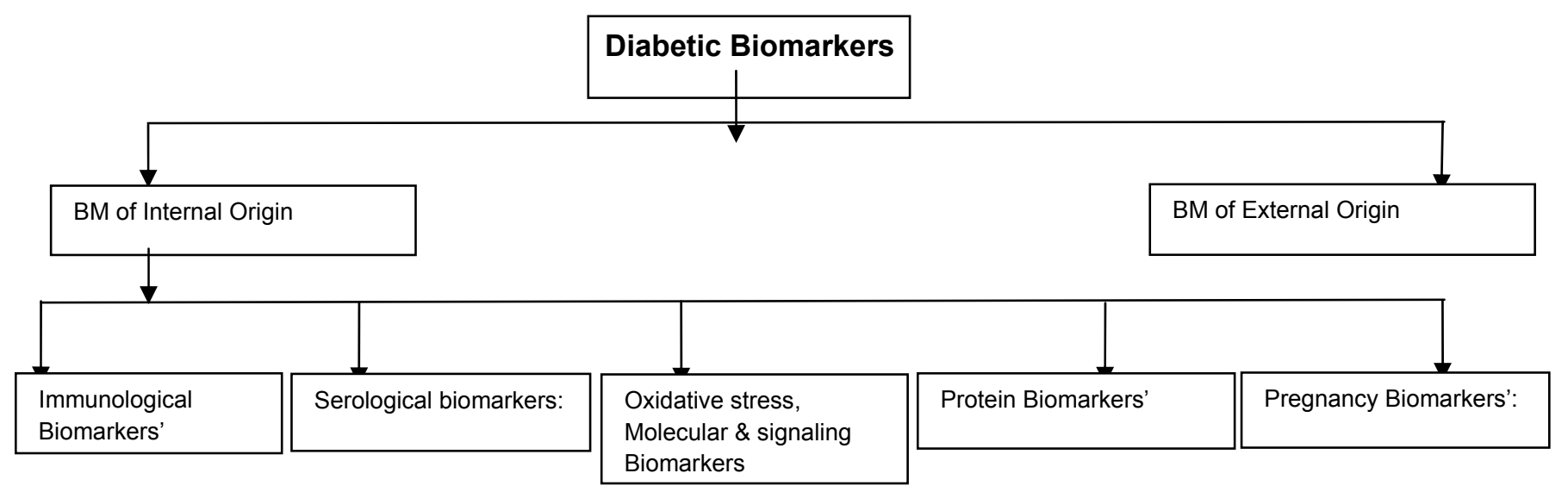

Table 1: The flow chart showing the topics discussed in this review.

with serum inflammatory biomarkers' and periodontal soreness in subjects with type 1 diabetes mellitus, the Study was done with Plaque, bleeding on probing and probing pocket depth (PD) were examined in 80 T1DM subjects at the baseline and in 58 subjects 8 weeks after periodontal therapy. The levels of glycosylated hemoglobin, serum interleukin (IL)-6, ultrasensitive C-reactive protein and the lipid profile were measured at the baseline and after therapy. The observed associations may be considered to be suggestive of a modulatory effect of IL-6 on host responses in T1DM subjects [10]. The IL-6 levels and External the combination of the CDI and pattern VEP techniques provides further interpretation of ocular circulatory changes in POAG patients [11]. The former were significantly higher in aqueous humor of POAG (Primary Open Angle Glaucoma) patients [12], this in turn is related to diabetes risk according to a survey made by an American organization. In contrast to this, steroidal eye drops prescription in Israel showed an increase in blood glucose level and has got marked alterations in glycemic control [13]. During the vascular injury IL-6 as a pro-inflammatory cytokine responds and which is observed by the blocking of STAT3 tyrosine phosphorylation, this is also related to the diabetic vascular complications, as hyperinsulinemia is associated with an increased risk of vascular restenosis after angioplasty [14].

Explorative role of CD38 and functionally associated molecular risk factors in a recently described chronic lymphocytic leukemia (CLL) nonobese diabetic/ severe combined immunodeficient xenograft model has been researched by Aydin S et al. [15]. though it does not contribute for diagnosis we hypothesized that this CD 38 can be useful in the detection of pancreatic cancers which will finally results in diabetes and the complications gives rise from diabetes, this methods have been a result from combined immune-staining methods includes immunoprecipitation and immunoblotting [15]. The other CD molecule which is associated with Diabetes is CD36 [16] where A cell-free form of CD36, soluble CD36 (sCD36), has been reported in human plasma, found to be elevated in obesity and diabetes, and claimed as a marker of insulin resistance [16]. The findings suggested that CD36 is not a proteolytic product, but rather is associated with a specific subset of circulating MPs that can readily be analysed. This finding will enable more specific investigations into the cellular source of the increased levels of plasma CD36 found in subjects with diabetes. The CD molecules have been a hope and scope in the Biomarker based methods.

Other Immunological factors which are associated with are lymphocytes [17], CLonal- $\beta$ cell [18], etc. Diabetes predisposes to periodontal disease. However, the cellular and molecular mechanisms are not clear which are linking each other. The impact of chronic hyperglycemia on leukocyte margination and macromolecule extravasation was determined in gingival vessels in vivo [17]. Chronic hyperglycemia induces a proinflammatory state in the gingival microcirculation characterized by increased vascular permeability, and leukocyte and endothelial cell activation. Leukocyte-induced microvascular damage, in turn, may contribute to periodontal tissue damage in diabetes. The study done with Gingival intravital microscopy measured extravasation of fluorescein isothiocyanate (FITC)-dextran in diabetic Akita and healthy wild-type (WT) mice. Rhodamine 6G and FITC-LY6G were injected for nonspecific and polymorphonuclearspecific leukocyte labeling, respectively. Surface expression of leukocyte adhesion molecules was determined with flow cytometry and western blotting. It was been hypothesized in use for the bio-indication in methods used for both the micro- and macro-vascular complications which will result in the hyperglycemic condition in case of Diabetes. In order to improve the odds of successful translation medicine the experiments on Immune modulators such as anti-thymoglobulin (ATG) have kept under clinical evaluation for the treatment of type 1 diabetes (T1D). Although such agents have cured T1D in the nonobese diabetic (NOD) model, their clinical efficacy is doubtful in development for virally infected (LCMV- infected). Therefore, the proposal to evaluate this agent under more stringent conditions has been dictated. In this experiment although the percentage of CD4(+) $\mathrm{CD} 25(+)$ regulatory $\mathrm{T}$ cells $(\mathrm{T}(\mathrm{regs}))$ within the $\mathrm{CD} 4(+)$ population was increased significantly after ATG therapy, their frequency in the periphery was reduced dramatically and never returned to normal baseline. The inability of ATG treatment to cure T1D in a stringent viral model (RIP-LCMV mice) is due at least partially to the inability to maintain or increase a sufficient CD4(+) CD25(+) T(regs) frequency, in striking contrast with what was reported in the NOD model.Thus this data would argue for the use of multiple animal models to assess efficacy of promising immune-based interventions and select the most potent therapies for future clinical trials. [19]

A plausible analysis of count of eosinophills is likely studied in diabetic prone $\mathrm{BB}$ rats, this study stated that eosinophilia has occurred at certain point of age, histological analyzes showed that eosinophilia correlates with eosinophil infiltration of islets and the latter correlates with severe insulitis, These findings indicate that eosinophilia is associated with a late stage of islet inflammation in diabetes prone BB rats independent of whether the animals develop diabetes or not [20]. For developing diagnosing tool for Eosinophilia, Fuzzy logic controller (FLC) is a potential tool [21], by this way the biomarker business of the eosinophills can be determined. 
We have reports previously that treatment of non-obese diabetic (NOD) mice with the invariant natural killer T (iNK T) cell agonist a-galactosylceramide C26:0 ( $\alpha$-GalCer) or its T helper type 2 (Th2)biasing derivative $\alpha$-GalCer $\mathrm{C} 20: 2$ (C20:2) protects against type 1 diabetes (T1D), with $\mathrm{C} 20: 2$ yielding greater protection [22]. We demonstrate that NOD iNK T cells activated during multi-dose (MD) treatment in vivo with $\mathrm{C} 20: 2$ enter into and exit from anergy more rapidly than after activation by $\alpha$-GalCer. Importantly, this shorter duration of iNK T cells in the anergic state promotes the more rapid induction of tolerogenic DCs and reduced iNK T cell death, and enables C20:2 stimulated iNK T cells to elicit enhanced protection from T1D. These findings further that suggest C20:2 is a more effective therapeutic drug than $\alpha-G a l C e r$ for protection from T1D. Moreover, the characteristics of $\mathrm{C} 20: 2$ provide a basis of selection of nextgeneration iNK T cell agonists for the prevention of T1D [22].

In complimentary to all the above markers the autoimmune disorders themselves will be the markers for T1DM. To determine the frequency of hypothyroidism, adrenocortical insufficiency, pernicious anemia, coeliac disease, vitiligo and systemic autoimmune disorders a reasonable study has been conducted. Autoimmunity was found to be consistently higher in females [23].

\section{Serological biomarkers}

A cohort study reveals that the serum levels of nitrites and nitrates meanwhile their levels in urine were used as biomarkers of the detection of the diabetic complications at early stages. In type 1 diabetes chronic hyperglycemia may act through a mechanism that involves increased NO production or action and contributes to generating intrarenal hemodynamic abnormalities which could be detectable by Doppler ultrasonography even before overt clinical nephropathy. Further follow up studies are needed to document the usefulness of Doppler ultrasound in detection of preclinical nephropathy [24].

Investigation of the redox state of human serum albumin concerning cysteine-34 (This albumin redox state concerning cysteine-34 was measured by high-performance liquid chromatography with fluorescence detection.) as a possible systemic redox marker in patients with different eye diseases with and without diabetic complications, Cataract (CAT), glaucoma, age-related macular degeneration (AMD), diabetes mellitus (DM), diabetic Retinopathy and hypertension were the pathologies investigated. Albumin as a systemic marker for oxidative stress was shifted to a more oxidized state by DM. Serum albumin is not shifted to more oxidized forms by localized oxidative stress, but it is in systemic diseases like DM [25].

C-reactive protein (CRP) is produced by the macrophages in the liver and adipocytes and is integrated in the acute-phase response pathway. Being a nonspecific marker of inflammation, it increases in response to inflammation. When used in combination with other established biomarkers for the prediction of the first major cardiovascular event or death, CRP does not improve the risk stratification obtained with the current guidelines. High-CRP concentrations are at a higher risk for atherosclerosis and CVD [26], the reduction of CRP levels itself or as a statin-related pleiotropic effect has been assessed in different scenarios, which include the acute phase of myocardial infarction; secondary prevention of cardiovascular diseases; special patient populations, such as diabetic patients and etc. Risk stratification in all the examined scenarios was related to serum LDL-C levels; in other words, the degree of cardiovascular risk was always lipid dependent [27].

The latest biomarker is termed to be Hemoglobulin (HbA 1c), Hemoglobin $\operatorname{HbA}(1 \mathrm{c})(\mathrm{A}(1 \mathrm{c}))$ has been used clinically since the 1980s as a test of glycemic control in individuals with diabetes [28]. The Diabetes Control and Complications Trial, the International Federation of Clinical Chemists (IFCC) and A(1c) -derived average glucose (ADAG) are the methods been discussed hereby. These were the alternative methods for the precise measurement of $\mathrm{A}(1 \mathrm{c})$. These propose the alternative methods for the tests of glycemic control in individuals with diabetes. As $\mathrm{HbA}(1 \mathrm{c})$ is a diagnosing and predicting biomarker in Type 2 diabetes with impaired glucose tolerance [29]. A study in Finnish population was done regarding the above criterion with two oral glucose tolerance tests. The sensitivity of the $\mathrm{HbA}(1 \mathrm{c}) \geq$ $6.5 \%$ ( $\geq 48 \mathrm{mmol} / \mathrm{mol}$ ) as a diagnostic criterion for Type 2 diabetes was differently varied in males and females, in spite of this discrimination at least we had a chance in the determination of $\mathrm{HbA}(1 \mathrm{c})$ as a biomarker. The other metabolic biomarkers which are related to the type 1 diabetes is Uridine [30]. The existence of a relationship between the degree of metabolic control of diabetes and pyrimidine metabolism presumably declares the analysis of uridine could be used as an adjunct marker of the severity of diabetic complications in newly diagnosed patients. Despite from the study a separate wing of study for the validate research on the relationship between the integrity of inner segment / outer segment (is /os) junction in OCT and final VA in patients, treated for diabetic macular edema states that the levels of HbAlc and other interfering factors don't show any significant differences [31]. Giving the ease and lower cost of measurement, HbAlc should be considered a beneficial diagnostic and prognostic alternative screening tool in the clinical setting [32].

\section{Oxidative stress Biomarkers}

Background hyperglycaemia and hyperinsulinaemia, hallmarks of the postprandial state, have been also associated with increased oxidative stress and lipoprotein oxidation contributing to vascular injury and atherosclerosis. But the study states that the correction of obesity and insulin resistance might be a useful strategy in counteracting systemic oxidative stress [33]. The oxidative stress conditions like glucotoxicity and lipotoxicity contribute to impaired $\beta$-cell function in type 2 diabetes. Interestingly, amino acid (AA) derangement is also a characteristic part of the diabetic state. The acute effects of AA on pancreatic $\beta$-cell function have been widely explored; however, to our knowledge, the chronic effects of AA, e.g. proline (Pro), homocysteine (Hcy), and leucine (Leu), on pancreatic $\beta$-cell function and integrity have not yet been studied. We aimed to investigate global alterations in $\beta$-cell gene expression after long-term exposure of clonal INS-1E cells to elevated level of specific AA in vitro. This concludes that AA appears to participate in and to influence many physiological processes including those involved in cholesterol metabolism, immune response [34]. The development of heart failure including disturbed cardiac stress response is a main complication of diabetes mellitus (DM). The characterization was done 'in vivo', under the cardiac stress response in the often used streptozotocin (STZ) rat model. There was an analysis of left ventricular (LV) performance of STZ-diabetic rats under basal and pharmacological stress conditions by recording pressure-volume loops using a micro conductance catheter at two different time points [35] The use of topical antioxidants to treat or delaying oxidative stressrelated ocular manifestations is still poorly explored in relation with Diabetic retinopathy [36]. In further, Lipid composition disturbances along with increased hyperglycemia which causes glycation of enzymes and oxidative stress causes the decrease in activity of $\mathrm{Na}^{+}-\mathrm{K}^{+}$-ATPase and other changes in erythrocyte membrane, this is purely can be used as the hematological bio-indicator for the prognosis for type- II diabetes [37]. 


\section{Molecular and Signaling Biomarkers}

S1PR2 is one of five known sphingosine-1-phosphate receptors and has recently been discussed to be implicated in the development or progression of diabetes, the aim in this cohort study is to determine the properties of S1PR2 which will result in the amino acids ambiguity in the code translation, this study concluded that the S1PR2 Val286Ala genotype to be significantly associated with incidence and age at onset of diabetes likely due to an altered function of S1PR2 [38]. Processed pseudo genes are non-functional copies of normal genes that arise by a process of mRNA retro transposition; they form a competent biomarker for a particular diseased condition like diabetes. The human genome contains thousands of pseudogenes; however, knowledge regarding their biological role is limited. High mobility group A1 (HMGA1) protein regulates the insulin receptor (INSR) gene and destabilization of HMGA1 mRNA is been observed this destabilization of HMGA1 mRNA is triggered by enhanced expression of RNA from an HMGA1 pseudogene, HMGA1-p, Targeted knockdown of HMGA1-p mRNA in patient cells results in a reciprocal increase in HMGA1 mRNA stability and expression levels with a parallel correction in cell-surface INSR expression and insulin binding. These data provide evidence that the linkage between pseudogene HMGA1-p expression and type 2 diabetes mellitus and it gives a conclusion that we can have limpid relationship between the HMGA1-p expression and type-2 diabetes [39].

The Liver X receptor alpha (LXR- $\alpha$ ) is a glucose sensor [40], the mutual study of the effect of the dosage of the glucose and fructose on the sensor and their further conformational studies can result in the development of the genealogical approach in the brightening up of biomarker developmental studies.

On the other hand the signaling pathways play an important role in for instance as we consider the EGFR signaling pathways. This is an investigation of the effect of the wound response in the corneal infarctions in the rats this can be studied in the end with the relation to the Human body [41]. As this can be studied by the use of the epithelial tissue of the respective origin at a desired experiment, as the $\mathrm{Xu} \mathrm{K}$ and et al. said this technique of staining by a fluorescent dye can be implemented in the human biopsies and etc. which will be a permissively astounding work for the development of a marker for the complications (diabetic).

In order to increase our understanding of diabetes-related muscle weakness, we carried out a mass spectrometry-based proteomic analysis of skeletal muscle preparations from the Goto-Kakizaki rat model of type- 2 diabetes. The abundance of the small stress proteins aB-crystallin and Hsp27 was significantly increased. The up-regulation of the low-molecular-mass heat shock protein Hsp27 was confirmed by an alternative fluorescent staining method of two-dimensional gels and immunoblotting. The observed protein alterations in the cellular stress response, distinct metabolic pathways, regulatory mechanisms and the contractile apparatus might be directly or indirectly associated with peripheral resistance to insulin signalling, making these newly identified muscle proteins potential biomarkers of type- 2 diabetes. Increased levels of molecular chaperones suggest considerably enhanced cellular stress levels in diabetic muscle fibres [42].

MicroRNAs (miRNAs) are short non-coding RNAs that modulate physiological and pathological processes by inhibiting target gene expression via blockade of protein translation and/ or by inducing mRNA degradation. These miRNAs potentially regulate the expression of thousands of proteins. miRNAs have been found to be functionally important in models of diabetic nephropathy and polycystic kidney disease. One miRNA (miR-192) can also act as an effector of transforming growth factor- $\beta$ activity in the high-glucose environment of diabetic nephropathy. Such a potential molecular marker of DN is said to be important in the phenomenon of bioindication of diabetic complications, the era of miRNA is yet to start, or already it has got started, is in a booming spark in these days [43]. The further clear approach in the biomarker development can be discussed in future and there will be integration of multiple 'Omics' sources, Omics data integration on the level of interaction networks furthermore provides a platform for identification of pathway-specific biomarkers and therapy options [44].

The HNF4- $\alpha$ is a gene which codes for the transcription factor which regulates the gene transcription and expression in pancreatic beta cells. Which leads to Maturity-Onset Diabetes of the Young (MODY), an uncommon and autosomal dominant, non-insulin dependent form of diabetes [84]. This provides us information for a start for further study to make the easier way of Prognosis, Diagnosis and treatment.

\section{Protein Biomarkers}

There are many protein biomarkers for the complications raised from that of diabetes there by one of them was Erectile dysfunction. In this case the Patients with erectile dysfunction (ED) associated with type II diabetes often have impaired endothelial function and tend to respond poorly to oral phosphodiesterase type 5 inhibitors. Therefore, neovascularization is a promising strategy for curing diabetic ED. Thus the potent angiogenic protein within the body is angiopoietin-1 [45], the effectiveness of this protein has been studied to prove it as the potent marker for the disease. The injection mode is through repeated intracavernous injections of COMP-Ang1 protein which completely restored erectile function and cavernous endothelial content through enhanced cavernous neoangiogenesis. Cavernous neovascularization using recombinant Ang1 protein is a novel strategy for the identification of ED in Diabetic complications. Similar case can be observed in ocular revascularization and can be treated by the Intravitreal injection of bevacizumab and Trabeculectomy with intraoperative sub-conjunctival injection of bevacizumab may offer a useful option for improving the outcome of filtering bleb in refractory glaucoma, the former is an easy, safe and effective modality of therapy for threshold disease ROP especially in presence of difficulties for laser photocoagulation $[46,47]$.

The other protein biomarker is Cystatin $\mathrm{C}$ which is a potent marker for the systematic study of hyperfiltration in diabetic nephropathy has been hindered by the lack of a simple glomerular filtration rate (GFR) measure that is accurate in this range of renal function [48]. This suggesting a role for cystatin $\mathrm{C}$ in clinical practice and research for the study of early renal function changes in Type 1 diabetes.

The Insulin itself in its zymogen form (Proinsulin) is a marker for diagnosis of insulinoma without hyperinsulinemia [49]. Patients with type 1 diabetes found to have lower serum osteocalcin, which results in a decreased activity of osteoblasts. Patients with poor glycemic control have lower serum osteocalcin, which can termed as the index for the diagnosis of the diabetes and the osteocalcin is the protein which can be termed as the protein biomarker in diabetes type I [50]. One of the complications arouse from the diabetes is cardio vascular disease the macro vascular complication in fact it is so. Individuals with type 2 diabetes are at higher risk of cardiovascular diseases (CVD) than those without type 2 diabetes. Individuals with the metabolic syndrome have a $61 \%$ higher risk of cardiovascular disease [51].

Assessment of selected parameters of dysfunction of endothelium 
such as concentration of soluble E-selectin (sE-selectin), soluble vascular cell adhesion molecule-1 (sVCAM-1), and soluble intracellular adhesion molecule-1 (sICAM-1) in women with pGDM can be taken into consideration as biomarker for DM, as an analysis has already been noted. The study done previously accomplished that in nondiabetic women with pGDM higher plasma sE-selectin level is not independently associated with the higher risk of pre-diabetic state. By this sE-selectin level is termed as marker of early cardio-metabolic risk due to its association with parameters of insulin resistance [52].

\section{Biomarkers of Diabetic Micro Vascular Complications}

Complications of diabetes are due to pathologic changes that involve small and large blood vessels, cranial and peripheral nerves, the skin, and the lens of the eye. A prevalence study in an outpatients' of a hospital stated that among the Complications of diabetes vascular complications are very high in pandemic conditions [53]. In that cardiovascular disease is the leading cause of morbidity and mortality in patients with diabetes mellitus. Diabetic patients with serious implications in the pathogenesis of vascular disease in patients with type 2 diabetes have get involved with their platelets and their count. Hyperglycemia changes platelet functions by impairing calcium homeostasis, in these situations Nifedipine is the compound which is reliable actually as Nifedipine therapy is useful for patients with diabetes mellitus type 2 from its effects on platelet aggregation, lipid metabolism and cardiovascular functions [54]. Patients with diabetes mellitus have a 2 to 4 times' higher risk of cardiovascular disease and up to a 3 times increase in mortality than non diabetics. The accelerated rate of atherosclerosis seen in diabetes mellitus predisposes patients to coronary artery disease and to higher rates of myocardial infarction [55]. Apart from that Retinopathy and nephropathy are micro vascular complications of diabetes; they are a result of an abnormal thickening of the basement membrane of the capillaries.

\section{Diabetic Retinopathy Biomarkers}

Diabetic retinopathy consists of micro aneurysms, hemorrhages, exudates, and retinal edema, as well as proliferation of newly formed vessels in some cases. Retinopathy may result in the loss of vision. Diabetic retinopathy is a highly specific vascular complication of both Type-I and Type-II diabetes. The prevalence of retinopathy is strongly related to the duration of diabetes. After 20 years of diabetes, nearly all patients with type I diabetes and $>60 \%$ of patients with Type II diabetes have some degree of retinopathy. It is the leading cause of blindness in the western world. In general, the progression of retinopathy is orderly, advancing from mild non-proliferative abnormalities, characterized by increased vascular permeability, to moderate and severe nonproliferative diabetic retinopathy (NPDR), characterized by vascular closure, to proliferative diabetic retinopathy (PDR), characterized by the growth of new blood vessels on the retina and posterior surface of the vitreous. Thus while investigating possible correlations between vitreous and/or serum levels of platelet-derived growth factor isoforms (PDGF$\mathrm{AA},-\mathrm{AB}$ and $-\mathrm{BB})$ with parameters associated with non-proliferative diabetic retinopathy (NPDR) the study stated that in addition to VEGF, almost all PDGF isoforms in the vitreous are also correlated with NPDR, this declaration is from the evaluation the concentrations of stem cell modulation factors such as Vascular Endothelial Growth Factor (VEGF), erythropoietin (Epo) etc in the peripheral blood of diabetic retinopathy patient [56]. Thus the VEGF is said to be one of the recent biomarker of Diabetic Retinopathy. The above study was accentuated case study with some significant association with Clinically Significant Macula Oedema (CSMO) [56]. The progression of NPDR to Proliferative diabetic retinopathy characterized by the growth of new blood vessels on the retina and posterior surface of the vitreous involving Several genetic polymorphisms have been identified which play a role in the occurrence and progression of renal dysfunction after cardiac surgery with cardiopulmonary bypass (CPB). Recently, it was demonstrated that the T allele of SNP rs1617640 in the promoter of the erythropoetin (EPO) gene is significantly associated with proliferative diabetic retinopathy (PDR) and end-stage renal disease (ESRD) due to increased EPO expression [57], and current diabetic retinopathy therapy includes invasive methods, like surgery. Ocular antioxidant potential therapy represents a non-invasive, safe and less painful methodology [58].

\section{Diabetic Nephropathy Biomarkers}

Diabetic nephropathy is a serious micro vascular complication of diabetes. Diabetes mellitus is the most common cause of end-stage renal disease. The risk factors for nephropathy are older age, male sex, non-Caucasian race, and poor blood pressure, glycemic, and lipid control. The kidneys have several important functions: excreting waste, maintaining blood pressure through the regulation of fluid and salts, production of erythropoietin (a regulator of red blood cell mass), and activation of vitamin D (a co-factor for calcium absorption). Normal kidney function involves the filtration of fluid from the blood and formation of urine. The early pathogenesis of diabetic nephropathy begins with hyperglycemia causing Glomerular hyperfiltration, which results in glomerular hypertrophy and glomerular basement membrane thickening. Early nephropathy also involves hemodynamic changes, including, decreased afferent and efferent arteriolar resistance, a dramatically increased plasma flow, and a moderately increased glomerular capillary pressure leading to an increased glomerular filtration rate (GFR). Subsequently, the GFR declines [59]. The GFR is defined as the volume of plasma that can be completely cleared of a particular substance by the kidneys in a unit of time. The gold standard for determining GFR has traditionally been inulin or isohexol but these techniques are invasive, expensive and time-consuming [60]. Renal disorders were significantly more common among keratoconus patients. The evaluation studies of the risk for osteoporosis, diabetes and hypertension in the patients with keratoconus were studied, thus the studies includes the mutual understanding of the diabetic complications which are associated with the renal failure [61] Microalbuminuria is one of the diseased conditions most often caused by kidney damage from diabetes. A study on the rate of formation of glycated albumin and comparison to that of glycohemoglobin, using a sensitive and specific immunoassay for measurement of the stable glucose adduct formed after incubation of serum, plasma and purified albumin with glucose. report that the rate of formation of glycated albumin parallels that of glycohemoglobin [62].

Thus the techniques used by the use of the biomarkers' are the way cheaper methods there are mostly Growth factors at molecular level and at genetic level they may be termed as genes and loci. Therapies with GF's as their weapons were being used for the treatment for instance CSII therapy decreased the frequency of hypoglycemia and improved glycemic variability, resulting in beneficial aspects for pregnant women with diabetes [63].

Molecular level biomarkers comprises of some growth factors, which are particularly well-established in contributing to fibrosis, such as the profibrotic, transforming growth factor- $\beta$, and connective tissue growth factor (CTGF), for the diagnosis of the Diabetic nephropathy is being tested by the inhibition of CTGF, a method for diagnosis [64].

At the level of genetics and chromosomal level of the determination 
it's a bit tougher in determination and also in performing the task. There are methods which are dependent mostly on the accentuated case studies. For instance polymorphisms in ACE and AGTR1 genes have been assessed in multiple studies for association with diabetic nephropathy. However those results are of conflicting manner. Thus the instinctive study was made by Currie D et al, in the sort of British population. This concomitantly gave a brief note on these two genes involved in Diabetic nephropathy along with their ability and importance in bio indication business [65]. By the hypothesis in the bio indication business of the genes as the biomarkers for the Diabetic Nephropathy, we can give a naive conclusion that those genetical biomarkers can be and will also be useful for in the bio indication process undoubtedly.

Diabetic encephalopathy is also a diabetic complication, which has been characterized by impaired spatial cognitive functions and the decline of learning and memory ability, involves direct neuronal damage caused by intracellular glucose. This is being corrected by the unique complex of vanadium [66].

\section{Pregnancy Biomarkers}

Gestational Diabetes Mellitus (GDM) incurs a risk of morbidity and mortality to mother, fetus and subsequent neonate which necessitates intensive monitoring and treatment [67] more importantly, glycemic variability have seen the sights as means of appraising glycemic control and anecdotal management in type 2 diabetes. Glycemic unpredictability and mean weekly glucose proportions can effortlessly be execute in the management of GDM. As both groups achieved target glycemic control and glycemic variability was the only parameter that improved over the study period, we believe that this may explain improved fetal and neonatal outcomes in the intervention arm [67]. A Nested case-control study (Routine first-trimester combined test) was performed on, to evaluate the value of first trimester placental biomarkers ( $\mathrm{f} \beta$-hCG, PAPP-A, ADAM12, PP13 and PlGF) in the prediction of macrosomia at birth in pre-gestational diabetes of both types [68] and also of maternal serum alpha-fetoprotein (MSAFP)[69]. Here in latter case study, ADAM12, PP13 and PlGF concentrations were measured in stored first-trimester serum, previously tested for $\mathrm{f} \beta$ hCG and PAPP-A. All concentrations were expressed as multiples of the median (MoM). Where applicable, the median MoMs of PGDM and control pregnancies were compared in relation to birth weight centiles. Model-predicted detection rates for fixed false-positive rates were obtained for statistically significant markers, separately and in combination, coming to the other study for MSAFP decreased second trimester levels have been reported were this study is of an existing dataset using women with pre-gestational diabetes who had routine MSAFP values available. Thus two different study designs have been studied which gave astonishing findings accordingly. The conclusions made from both the studies were that normal levels of the markers' biologically are enough in predicting the Macrosomia at birth in PostGestational Diabetic women the fetal birth weight in PGDM offspring is partially determined by placental development. The increase in fetal macrosomia may be related to better early glycemic control and placentation [68]. In other study simultaneously the MSAF protein has been reported as a biomarker in pre-gestational diabetes decrease in its concentration during the second trimester levels of MSAF protein is said to be the significance of PGD- Post Gestational Diabetes [69]. During the gestational period and more keenly during the pregnancy myometrial wall expresses increased release in the glucocorticoids [70] and these glucocorticoids increase will reflects that the insulin sensitivity decreases [71]. This may also be able to lead to the gestational diabetes if these expressed glucocorticoids go to circulation when they are in excess. The sensitization of the insulin is being studied by simple and unique tests which are merely Fasting plasma glucose (FPG), fasting plasma insulin (FPI) and calculation of number of erythrocyte insulin receptors (NO-EIR) tests. It appears that insulin sensitivity could be defined as molar ratio of available NO-EIR molecules per molecule of FPI [72]. Women with previous gestational diabetes (pGDM) represent a high risk group for type 2 diabetes and for cardiovascular disease in the future.

\section{Glycemic Control Aspects}

In some studies all diabetic patients when provided knowledge, and with attitude, self-care adherence were not found to have significant relationships with glycemic control [73], and in some studies they were taken into consideration [74]. If given proper education and guidance regarding foot care would be able to make a significant improvement in their life style which is helpful to avoid amputations. These are some of the alternative methods and methods to control the glycemic index, the pharmaceutical approach in which BIAsp 30 [75] and Imeglimin [76] - A new oral anti-diabetic that targets the three key defects of type 2 diabetes, the former, Biphasic Insulin Aspart 30 is used to decrease the higher glycemic levels, this is termed to be effective in the lowering of the glycemic levels. To make clear of the prognosis process and well understanding of the Glycemic control aspects, few devices have been developed [77]. Despite of all the other studies the web-based method seems to be effective in the continuing education [78]. In some cohort and endemic studies drinking alcohol with certain quantity is affiliated with a reduced risk of type II diabetes [79]. Meanwhile we can evaluate the glycemic control efficacy by some of the factors or compounds like Bromocriptine-QR, routine of addition of the latter to the Thiazolidinedione treatment improved glycemic control [81]. Carnitine deficiency is associated with hypoglycemia and what we call the glycemic control in type I diabetis mellitus [83]. From all the above we should understand that the approach for the lowering of glycemic control should be the combination of life style modification (diet and exercise) and antihyperglycemic agents in order to achieve adequate glycemic control [85].

\section{Insulin Analogues}

Before going into the matter, once we can ask ourselves by completing the view on this review, That is nothing but "do we need another insulin?" This review concludes that we need so. We have some of them in the c0ommercial market for instance Insulin Lispro, Insulin glulisine etc. Both get absorbed faster than regular insulin. Insulin glulisine is the newest of the rapid acting insulin analogues, as it is derived from human insulin by replacement of AspB3 by Lys and LysB29 by Glu. Meanwhile Insulin lispro was developed by modification at the B26-30 regions [80]. Use of combinational idea with insulin glargine, U-500 regular insulin and pramlintide is used for the patients with type II diabetes variants extremely in obese patients. It improved the probability of observance [82].

\section{References}

1. Ragheb R, Medhat AM (2011) Mechanisms of Fatty Acid-Induced Insulin Resistance in Muscle and Liver. J Diabetes Metab 2:127.

2. Ramachandran A, Moses A, Snehalatha C, Shetty AS, Seeli AC, et al. (2011) Assessment of Sudomotor Function to Predict Future Abnormalities of Glucose Tolerance in at Risk Population. J Diabetes Metab 2:125

3. Shanker JH, Mahmood SE, Joshi MC, Shaifali I (2011) Obesity Indices amongst Diabetics in an Urban Population of Western Nepal. J Diabetes Metab 2:134. 
Citation: Sai YRKM, Dattatreya A, Anand SY, SureshBabu D, Sandeep Heni RS (2011) Biomarkers of Internal Origin and Their Significance in Diabetes and Diabetic Complications. J Diabetes Metab R1:001. doi:10.4172/2155-6156.R1-001

4. Mansour AA, Wanoose HL, Odaa AH (2011) A Three Year Cohort Prospective Type 2 Diabetes Control Study in Basrah. J Diabetes Metab 2:119.

5. Mungrue K, Roper LA, Chung T (2011) Assessment of Weight Loss in the Management of Patients with Type 2 Diabetes Mellitus in Primary Care in Trinidad. J Diabetes Metab 2:120.

6. Kablan A, Saunders RA, Szkudlarek-Mikho M, Chin JB, Bosio RM, et al. (2010) Prieurianin Causes Weight Loss in Diet-Induced Obese Mice and Inhibits Adipogenesis in Cultured Preadipocytes. J Diabetes Metab 1:101.

7. Ribeiro C, de Alencar Mota CS, Voltarelli FA, de Araújo MB, Botezelli JD, et al. (2010) Effects of Moderate Intensity Physical Training in Neonatal AlloxanAdministered Rats. J Diabetes Metab 1:107.

8. Bence-Jones, H 1847. Papers on Chemical Pathology: Lecture III. Lancet ii: 269-272.

9. Kyle, RA 1994: Multiple myeloma: How did it begin? Mayo Clin Proc

10. Passoja A, Knuuttila M, Hiltunen L, Karttunen R, Niemelä O, et al. (2011) Serum interleukin-6 may modulate periodontal inflammation in type 1 diabetic subjects. J Clin Periodontol 38: 687-693.

11. Mokbel TH, Ghanem AA (2011) Diagnostic Value of Color Doppler Imaging and Pattern Visual Evoked Potential in Primary Open-Angle Glaucoma. J Clinic Experiment Ophthalmol 2:127.

12. Ghanem AA, Arafa LF, Elewa AM (2011) Tumor Necrosis Factor- $\alpha$ and Interleukin-6 Levels in Patients with Primary Open-Angle Glaucoma. J Clinic Experiment Ophthalmol 2:118.

13. Bahar I, Vinker S, Kaiserman I (2011) The Effect of Topical Steroids on Blood Glucose Profile in Diabetic Patients. J Clinic Experiment Ophthalmol 2:133.

14. Chang Y (2011) A Central Role of PTP1B in Hyperinsulinemia-Enhanced IL-6 Signaling in Dedifferentiated Vascular Smooth Muscle Cells. J Diabetes Metab 2:118.

15. Aydin S, Grabellus F, Eisele L, Möllmann M, Hanoun M, et al. (2011) Investigating the role of CD38 and functionally related molecular risk factors in the CLL NOD/SCID xenograft model. Eur J Haematol 87: 10-19.

16. Alkhatatbeh MJ, Mhaidat NM, Enjeti AK, Lincz LF, Thorne RF, (2011) The putative diabetic plasma marker, soluble CD36, is non-cleaved, non-soluble and entirely associated with microparticles. J Thromb Haemost. 9: 844-851.

17. Sima C, Rhourida K, Van Dyke TE, Gyurko R. (2010) Type 1 diabetes predisposes to enhanced gingival leukocyte margination and macromolecule extravasation in vivo. J Periodontal Res. 45: 748-756.

18. Liu Z, Luo Y, Jeppesen PB, Gregersen S, Hermansen K, (2011) Amino acidinduced gene expression profiling in clonal $\beta$-cell line INS-1E cells. Diabetes Metab Res Rev. 27: 120-176.

19. Bresson D, von Herrath MG, Anti-thymoglobulin (ATG) treatment does no reverse type 1 diabetes in the acute virally induced rat insulin promoterlymphocytic choriomeningitis virus (RIP-LCMV) model. (2011) Clin Exp Immunol. 163: 375-380.

20. Maruta K, Treichel U, Kolb-Bachofen V, Kolb H (1989) Prospective analysis of eosinophilia in spontaneously diabetic BB rats: correlation with isle inflammation but not with diabetes development. Diabetes Research 11: 173176

21. Merlyn SM, Valentina SS, Singh S, Vennila JJ, Kumar A (2010) Application of Artificial Intelligence in the Diagnosis of Eosinophilia. J Health Med Informat $1: 103$

22. Tohn R, Blumenfeld H, Haeryfar SM, Veerapen N, Besra GS, et al. (2011) Stimulation of a shorter duration in the state of anergy by an invariant natural killer T cell agonist enhances its efficiency of protection from type 1 diabetes. Clin Exp Immunol. 164: 26-41.

23. Joffe B, Distiller L, Landau S, Blacking L, Klisiewicz A (2010) Spectrum of Autoimmune Disorders in Type 1 Diabetes - A Cross-Sectional Clinical Audit. J Diabetes Metab 1:112.

24. El Asrar MA, Adly AAM, El Hadidi E, Gharib M (2011) Serum and Urinary Nitrites and Nitrates and Doppler Sonography in Detection of Early Diabetic Complications. J Diabetes Metab 2:117.

25. Oettl K, Reibnegger G, Schmut O (2011) The redox state of human serum albumin in eye diseases with and without complications. Acta Ophthalmol. 89 e174-179.
26. Calle MC, Vega-López S, Segura-Pérez S, Volek JS, Pérez-Escamilla R, et al. (2010) Low Plasma Hdl Cholesterol and Elevated C Reactive Protein further Increase Cardiovascular Disease Risk in Latinos with Type 2 Diabetes. J Diabetes Metab 1:109.

27. Martínez VB, González-Juanatey JR (2009) Markers of inflammation and cardiovascular disease: clinical applications of $C$-reactive protein determination. Am J Cardiovasc Drugs. 1: 3-7.

28. Gallagher EJ, Le Roith D, Bloomgarden Z (2009) Review of hemoglobin A(1c) in the management of diabetes. J Diabetes. 1: 9-17.

29. Pajunen P, Peltonen M, Eriksson JG, Ilanne-Parikka P, Aunola S, et al. (2011) $\mathrm{HbA}(1 \mathrm{c})$ in diagnosing and predicting Type 2 diabetes in impaired glucose tolerance: the Finnish Diabetes Prevention Study. Finnish Diabetes Prevention Study. Diabet Med. 28: 36-42.

30. Dudzinska W (2011) Uridine correlates with the concentration of fructosamine and $\mathrm{HbA} 1 \mathrm{c}$ in children with type 1 diabetes. Acta Paediatr. 100: 712-716.

31. Abdollahi A, Esshghabadi A, Faghihi H, Mirshahi A (2011) The Relationship between Central Macular Photoreceptor Status and Final Visual Acuity in Resolved Diabetic Macular Edema by Nonsurgical Treatment. J Clinic Experiment Ophthalmol 2:157.

32. Reddigan JI, Ardern Cl, Riddell MC, Kuk JL (2010) Differences in the Association between Clinically Relevant Classifi cations of Glycemia Measures and All-Cause and Cardiovascular Disease Mortality Risk. J Diabetes Metab $1: 106$

33. D’Archivio M, Annuzzi G, Varì R, Filesi C, Giacco R, et al. (2011) Predominant role of obesity/insulin resistance in oxidative stress development. Eur $\mathrm{J}$ Clin Invest.

34. Liu Z, Luo Y, Jeppesen PB, Gregersen S, Hermansen K (2011) Amino acidinduced gene expression profiling in clonal $\beta$-cell line INS-1E cells. Diabetes Metab Res Rev. 27: 120-176.

35. Riad A, Westermann D, Felix SB, Schultheiss HP, Tschope C (2010) Reduced Cardiac Performance after Differential Pharmacological Stress in Streptozotocin-Induced Diabetic Rats. J Clinic Experiment Cardiol 1:108.

36. da Silva SB, Costa JP, Pintado ME, Ferreira DC, Sarmento B (2010) Antioxidants in the Prevention and Treatment of Diabetic Retinopathy - A Review. J Diabetes Metab 1:111.

37. Kumar R, Kumar AN, Ahmed S (2011) Changes in Erythrocyte Membrane in Type-li Diabetes Mellitus with and without Dyslipidemia. J Diabetes Metab 2:141.

38. Kozian DH, Evers A, Schäfer M, März W, Böhm BO, et al. (2010) A Nove Val286Ala Polymorphism in the NPXXY Motif of the Sphingosine-1-Phosphate Receptor S1PR2 Associates with the Incidence and Age of Onset of Diabetes. J Diabetes Metab 1:113.

39. Chiefari E, liritano S, Paonessa F, Le Pera I, Arcidiacono B, et al. (2010) Pseudogene-mediated posttranscriptional silencing of HMGA1 can result in insulin resistance and type 2 diabetes. Nat Commun. 1: 40

40. Dave VP, Mehrotra A, Kaul D (2011) Hyperglycemic-dependent LXR-alpha Gene Regulation within Blood Mononuclear Cells of CHD Patients. J Clinic Experiment Cardiol 2:117.

41. Xu K, Yu FS (2011) Impaired epithelial wound healing and EGFR signaling pathways in the corneas of diabetic rats. Invest Ophthalmol Vis Sci. 52: 3301 3308

42. Mullen E, O'Reilly E, Ohlendieck K, (2011) Skeletal muscle tissue from the Goto-Kakizaki rat model of type-2 diabetes exhibits increased levels of the small heat shock protein Hsp27. Mol Med Report. 4: 229-236.

43. Li JY, Yong TY, Michael MZ, Gleadle JM, (2010) Review: The role of microRNAs in kidney disease. Nephrology (Carlton). 15: 599-608.

44. Fechete R, Heinzel A, Perco P, Mönks K, Söllner J, et al. (2011) Mapping of molecular pathways, biomarkers and drug targets for diabetic nephropathy. Proteomics Clin Appl. 5: 354-366.

45. Jin HR, Kim WJ, Song JS, Piao S, Tumurbaatar M et al (2010) Intracavernous delivery of synthetic angiopoietin-1 protein as a novel therapeutic strategy for erectile dysfunction in the type II diabetic $\mathrm{db} / \mathrm{db}$ mouse. J Sex Med 7: 3635 3646

46. Salman AG (2010) Intravitreal Bevacizumab Injection as a Primary Therapy for Threshold Disease (ROP) in Al Qassim Region. J Clinic Experiment Ophthalmol 1:113. 
Citation: Sai YRKM, Dattatreya A, Anand SY, SureshBabu D, Sandeep Heni RS (2011) Biomarkers of Internal Origin and Their Significance in Diabetes and Diabetic Complications. J Diabetes Metab R1:001. doi:10.4172/2155-6156.R1-001

47. Ghanem AA (2011) Trabeculectomy with or without Intraoperative Subconjunctival Injection of Bevacizumab in Treating Refractory Glaucoma. J Clinic Experiment Ophthalmol 2:131.

48. Cherney DZ, Sochett EB, Dekker MG, Perkins BA (2010) Ability of cystatin C to detect acute changes in glomerular filtration rate provoked by hyperglycaemia in uncomplicated Type 1 diabetes. Diabet Med. 27: 1358-1365.

49. Furushima K, Tone A, Katayama A, Iseda I, Higuchi C, et al. (2010) A Case of Proinsulin-Secreting Malignant Insulinoma in an Elderly Patient with Cerebral Infarction. J Diabetes Metab 1:103.

50. Abo-El-Asrar M, Farid SM, Maraghy MOE, Mohamedeen AK (2011) Serum Osteocalcin, Zinc Nutritive Status and Bone Turnover in Children and Adolescents with Type1 Diabetes Mellitus. J Diabetes Metab 2:128.

51. Taloyan M, Saleh-Stattin N, Johansson SE, Agréus L, Wändell P (2010) Differences in Cardiovascular Risk Factors in Swedes and Assyrians/ Syrians with Type 2 Diabetes: Association with Lifestyle-Related Factors. J Diabetes Metab 1:110

52. Alina S, Barbara R, Krzysztof G, Barbara G, Marek G, et al. (2011) Elevation of sE-Selectin Levels from 2-24 Months Following Gestational Diabetes is Associated with Early Cardiometabolic Risk in Non-Diabetic Women. J Diabetes Metab 2:138.

53. Abougalambou SSI, Hassali MA, Sulaiman SAS, Abougalambou AS (2011) Prevalence of Vascular Complications among Type 2 Diabetes Mellitus Outpatients at Teaching Hospital in Malaysia. J Diabetes Metab 2:115

54. Emara E, Abdel-Sater KA (2011) Beneficial Effects of Calcium Channel Blocker "Nifedipine" on Abnormalities of Platelets and Lipid Metabolism in Patients with Type II Diabetes Mellitus. J Diabetes Metab 2:131

55. Li YW, Aronow WS (2011) Diabetes Mellitus and Cardiovascular Disease. J Clinic Experiment Cardiol 2:114.

56. Praidou A, Papakonstantinou E, Androudi S, Georgiadis N, Karakiulakis G et al (2011) Vitreous and serum levels of vascular endothelial growth factor and platelet-derived growth factor and their correlation in patients with nonproliferative diabetic retinopathy and clinically significant macula oedema. Acta Ophthalmol 89: 248-254

57. Popov AF, Schulz EG, Schmitto JD, Coskun KO, Tzvetkov MV et al ( 2010) Relation between renal dysfunction requiring renal replacement therapy and promoter polymorphism of the erythropoietin gene in cardiac surgery. Artif Organs 34: 961-968.

58. da Silva SB, Costa JP, Pintado ME, Ferreira DC, Sarmento B (2010) Antioxidants in the Prevention and Treatment of Diabetic Retinopathy - A Review. J Diabetes Metab 1:111.

59. American diabetes association, standars of medical care in diabetes. Diabetic care. 28 (supply 1):S4-36

60. Van Dijk C, Berl T, et al.. Pathogenesis of diabetic nephropathy. Reviews in Endocrine \& Metabolic Disorders. 5: 237-248.

61. Bahar I, Vinker S, Livny E, Kaiserman I (2010) Possible Association between Keratoconus and Renal Diseases. J Clinic Experiment Ophthalmol 1:112.

62. Cohen MP, Hud E, Shea E (2010) Rate of Formation of Glycated Albumin Revisited and Clinical Implications. J Diabetes Metab 1: 102.

63. Higuchi C, Tone A, Iseda I, Tsukamoto K, Katayama A, et al. (2010) A Pregnan Patient with Brittle Type 1 DiabetesSuccessfully Managed by CSII Therapy with Insulin Aspart. J Diabetes Metab 1:104.

64. Boor $P$, Floege J (2011) Chronic kidney disease growth factors in renal fibrosis. Clin Exp Pharmacol Physiol. 38: 391-400.

65. Currie D, McKnight AJ, Patterson CC, Sadlier DM, Maxwell AP et al (2010) Investigation of ACE, ACE2 and AGTR1 genes for association with nephropathy in Type 1 diabetes mellitus. Diabet Med. 27: 1188-1194.

66. Chen $D$, Huang $H$, Xing $Y$, Liu $Y, X u Y$, et al. (2011) A New Vanadium Complex Improves the Spatial Learning and Memory by Activation of Caveolin-MAPKCREB Pathway in Diabetic Mice. J Diabetes Metab 2:114

67. Lemos Costa TMR, Detsch JM, Pimazoni-Netto A, de Almeida ACR, SztalMazer S, et al. (2011) Glycemic Variability and Mean Weekly Glucose in the Evaluation and Treatment of Blood Glucose in Gestational Diabetes Mellitus: Evidence for Lower Neonatal Complications. J Diabetes Metab 2:137.

68. Kuc S, Wortelboer EJ, Koster MP, de Valk HW, Schielen PC et al (2011) Prediction of macrosomia at birth in type- 1 and 2 diabetic pregnancies with biomarkers of early placentation. BJOG 118: 748-754.
69. Sprawka N, Lambert-Messerlian G, Palomaki GE, Eklund EE, Canick JA (2011) Adjustment of maternal serum alpha-fetoprotein levels in women with pre-gestational diabetes. Prenat Diagn 31: 282-285.

70. Sethna F, Tyson-capper AJ, Shiells EA, Robson SC (2011) Expression of Glucocorticoid Receptor in Human Myometrium during Pregnancy and Labour. J Steroids Hormon Sci 2:104

71. Mcmahon M, Gerich J, Rizza R (2009) Effects of glucocorticoids on carbohydrate metabolism. Issue Diabetes/Metabolism Reviews 4: 17-30.

72. Ramulu P, Giridharan, Udayasekhararao $P$, Janardanasarma MK (2011) Insulin Sensitization and Resistance Interrelationship in a Pre-diabetic Rat: A Quantitative Molecular Model. J Diabetes Metab 2:140.

73. Patra SR, Jahnavi G (2011) An Improvement in Compliance for Foot Care in Persons with Type 2 Diabetes with a Teaching Session. J Diabetes Metab $2: 130$

74. Al-Akour NA, Khader YS, Alaoui AM (2011) Glycemic Control and Its Determinants among Patients with type 2 Diabetes Mellitus Attending a Teaching Hospital. J Diabetes Metab 2:129.

75. Esteghamati A, Nakhjavani M, Aminorroaya A, Aboutorabi R, M Niafar, et al. (2011) Biphasic Insulin Aspart 30 (BIAsp 30) is Safe and Improves Glycaemic Control in Insulin Naïve Patients with Type 2 Diabetes. J Diabetes Metab 2:123.

76. Fouqueray P, Leverve X, Fontaine E, Baquié M, Wollheim C, et al. (2011) Imeglimin - A New Oradl Anti-Diabetic that Targets the Three Key Defects of type 2 Diabetes. J Diabetes Metab 2:126.

77. David SK, Upadhayaya N, Siddiqui MK, Usmani AM (2010) Knowledge Discovery Technique for Web-Based Diabetes Educational System. J Health Med Informat 1:102.

78. Li H, Wang G, Wang A, Tong W, Zhang Y (2011) Alcohol Consumption and Risk of Type 2 Diabetes in Mongolian Population, Inner Mongolia, China. J Diabetes Metab 2:116.

79. Ramachandra S (2011) Do we need yet another Insulin? J Diabetes Metab 2:0e4.

80. Florez H, Scranton R, Farwell WR, DeFronzo RA, Ezrokhi M, et al. (2011) Randomized Clinical Trial Assessing the Efficacy and Safety of BromocriptineQR when Added to Ongoing Thiazolidinedione Therapy in Patients with Type 2 Diabetes Mellitus. J Diabetes Metab 2:142.

81. Nichol A, ChandraSekar M (2011) Successful Management of Extremely Insulin-Resistant Obese Diabetic Patient with Insulin Glargine, U-500 Regular Insulin and Pramlintide. J Diabetes Metab 2:143.

82. Jacobson JD, Midyett LK, Garg U, Sherman AK, Patel C (2011) Biochemica Evidence for Reduced Carnitine Palmitoyl Transferase 1 (CPT-1) Activity in Type 1 Diabetes Mellitus. J Diabetes Metab 2:144

83. Hellwege JN, Hicks PJ, Palmer ND, Maggie CYN, Freedman BI, et al. (2011) Examination of Rare Variants in HNF4a in European Americans with Type 2 Diabetes. J Diabetes Metab 2:145.

84. Shehata MF, Pater A (2011) Incretin-Based Therapies: What Do We Need To Know? J Diabetes Metab 2:146. 